\title{
Cognitive Status of Contemporary College Students on Excellent Traditional Culture and Analysis of Educational Countermeasures
}

\author{
-Li Fenghui: College of Marxism, Jiangxi Normal University, Jiang Xi province, Nan Chang City, China. \\ Pan Yilin: College of Marxism, Jiangxi Normal University, Jiang Xi province, Nan Chang City, China.
}

\begin{abstract}
Chinese excellent traditional culture is the spiritual blood of the Chinese nation, the gene of the nation and the important source of thought in the process of Chinese people to be in a position to maintain the rule of law and respect, and to respect the position of the time, to become a member of the people, to become a member of the public and to build a work and work. However the young generation represented by college students shoulders the mission of history and times, but the cognition of excellent traditional culture in our country is not optimistic. The reason is that the culture itself, students, families, schools, social environment and other aspects, how to preach well, inherit the excellent Chinese traditional culture, and play an important role has become an urgent need to solve the major problems.
\end{abstract}

Key words: Excellent traditional culture, College student, Present situation, Strategy.

\section{Introduction}

Xi Jinping pointed out that "The rich philosophical thoughts, humanistic spirit, edification thoughts, and moral concepts of China's excellent traditional culture can provide useful enlightenment for people to understand and transform the world, provide useful enlightenment for ruling the country, and provide useful benefits for moral construction. For the content of traditional culture that is suitable for regulating social relations and encouraging people to go up to the good, we must inherit and carry forward the new meaning in light of the conditions of the times" (Jinping's, 2014) To further inherit and promote the Chinese traditional culture, understand the cognitive status of contemporary college students on excellent traditional culture, the research group conducted a questionnaire survey on college students. The questionnaire was based on the theme of "Excellent Traditional Culture Conserving Contemporary University Values Methodology", focusing on college students' understanding of excellent traditional culture, the influencing factors and the practice situation. The questionnaire involved 21,006 valid questionnaires in East China, Central China, South China and Southwest China. Among them, the proportion of male students was $45.58 \%$, and the proportion of female students was $54.42 \%$. The survey results objectively reflect the overall situation of contemporary college students' understanding of excellent traditional culture.

\section{The Status Quo of College Students' Understanding of Excellent Traditional Culture}

\subsection{The Cognition of Traditional Culture for Students is More Superficial}

The Chinese traditional culture is the blood and genes for the nation. However, from the survey, the contemporary college students' understanding of traditional culture is more superficial and they lack inner recognition. From the perspective of subjective attitudes, the survey shows that students who like "love and 
willing to learn and understand" Chinese traditional culture account for $87.25 \%$ of the total sample, and "not interested" only account for $3.45 \%$. The data show that the majority of college students are positive about the subjective attitude of traditional culture, and they are willing to further study and understand, which provides potential opportunities for colleges to promote excellent traditional culture, and shows the reality of demand.

Table-1. Attitudes towards traditional culture (\%).

\begin{tabular}{lll}
\hline $\begin{array}{l}\text { Like, and willing to learn } \\
\text { to understand }\end{array}$ & $\begin{array}{l}\text { No feeling, little } \\
\text { relationship with myself }\end{array}$ & $\begin{array}{l}\text { Not interested, not related } \\
\text { to myself }\end{array}$ \\
\hline 87.25 & 17.08 & 3.45 \\
\hline
\end{tabular}

However, when asked about "the attitude towards the ancient history of history", the vast majority of students only occasionally read (71.93\%), and a considerable number of students are far away (10.36\%).

Table-2. Attitudes towards the ancient history of history (\%).

\begin{tabular}{llll}
\hline Very like & Occasionally read & Far away & Deep hate \\
\hline 16.48 & 71.93 & 10.36 & 1.23 \\
\hline
\end{tabular}

It can be seen that college students only stay in a general and vague subjective perception level for traditional culture. They know it is beneficial to know the excellent traditional culture and subjectively express their love for it. However when it comes to specific books carrying excellent traditional culture, they lack of in-depth understanding and even subjective preferences are greatly reduced.

From a behavioral point of view, the survey shows that the dates on practicing the traditional Chinese etiquette in daily life, "the students who pay attention to the moment account for $35.85 \%$, students who sometimes pay attention to account for $61.6 \%$, and students who never pay attention to account for $2.48 \%$. This shows that college students lack deep recognition about the excellent traditional culture, and their cognition only stay at the surface. They are not practicing the saying that "the unity of knowing and doing". Only by internalizing the concept in the heart, they can practice it on our daily life. There is a saying that "Not only the gaining of principle, but also forming of character needs practice. "From the current data, there is still a long way to go before the excellent traditional culture conserves the values of college students.

\subsection{Failing to Pay Attention to the Reading of Traditional Culture Books}

Reading is one of the most direct, convenient and effective ways to learn, understand and master excellent traditional culture. It has an irreplaceable role for college students to acquire relevant knowledge. However, the data from the survey shows that college students are not optimistic about the reading of traditional culture books. Only $17.87 \%$ of the students read the traditional Chinese classics regularly, and the occasional reading accounted for $67.54 \%$.

Table-3. Frequency of reading traditional Chinese classics (\%)

\begin{tabular}{llll}
\hline Often reading & Occasionally reading & Never reading & others \\
\hline 17.87 & 67.54 & 11.15 & 3.43 \\
\hline
\end{tabular}

From the frequency point of view, most students only read occasionally, showing that the proportion of not reading and reading frequently is small, and the proportion of occasional reading is more bigger. In addition, $74.65 \%$ of the students were within 10 books when asked about "the ancient books and books that have been read in addition to the class, and how many other ancient books have been read." From elementary school entrance to university, every college student has gone through at least 12 years of study career. In other words, since the entrance to the school, the vast majority of young people represented by college students have read less than one book per year on extracurricular ancient books.

Table-4. How many extracurricular books have been read (\%).

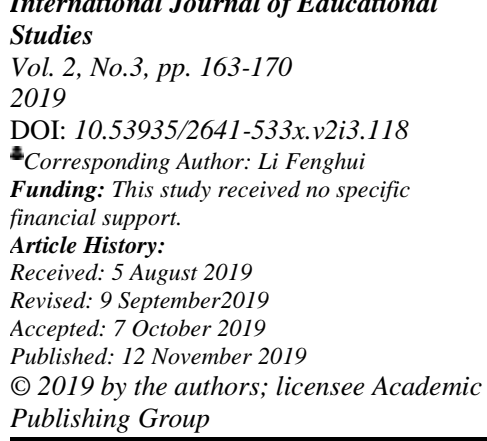

\begin{tabular}{llll}
\multicolumn{4}{c}{ Table-4. How many extracurricular books have been read (\%). } \\
\hline Within 10 books & $\mathbf{1 1 - 2 0}$ books & $\mathbf{2 1}$ books above & $\mathbf{0}$ \\
\hline 74.65 & 18.61 & 5.75 & 0.99 \\
\hline
\end{tabular}


In terms of quantity, college students' reading of traditional culture books basically stays in the classroom. In the group of college students, there is a lot of room for improvement in intensive reading.

\subsection{Insufficient Understanding and Comprehending of Traditional Festivals}

Chinese traditional festivals are diverse in form and rich in content, and are an important part of the long history and culture of the Chinese nation. Traditional festivals are also an important carrier and mode of dissemination of Chinese excellent traditional culture. It contains profound national sentiments and historical traditions. It is an effective way of national unity and cultural inheritance, and an important part of improving students' cultural accomplishment and cultural identity. According to the survey, for the question that "Can you tell which traditional cultural festivals and know their time?" The top four answers are: "The Magpie Festival (average composite score 3.05\%), February 14 Valentine's Day (2.57\%), Western Ghost Festival $(1.28 \%)$, Christmas $(1.27 \%)$, only one of the four festivals is a traditional Chinese festival. Obviously, on the university campus, the conception of celebrating traditional Chinese festivals are gradually weakening. Western festivals such as Valentine's Day, April Fool's Day, Christmas, Halloween, etc. are popular on campus. There are some reasons can be contributing to the phenomenon. First, there is a lack of understanding of the connotation of traditional festivals, and there is little knowledge about the profound national sentiments and historical sources. Second, the traditional festivals have a single form. With the development of the times and the influence of fast-paced lifestyles, Chinese are gradually simplified the original rituals of traditional festivals. In addition, influenced by Western ideology and culture, the invasion of Western culture, and the export of values, college students are more enthusiastic about the foreign festivals.

\subsection{The Entertainment Tendency in College Students is More Serious}

As early as the 1980s, Neil Postman once pointed out in his masterpiece Entertainment to Death: "All public discourses are increasingly appearing in an entertaining way and become a cultural spirit. Our Politics, religion, journalism, sports, education, and business are willing to become vassals of entertainment, without complaints or even silence, and as a result, we become a species of entertainment to death." Neil (2004) it should be noted that the entertainment tendency of cultural communication has become increasingly apparent with the exchange of culture, the introduction of Western culture, the popularization and development of the Internet. According to the survey, when asked "How to increase your interest in Chinese traditional culture (multiple choices)", 67,04\% of students hope to present relevant short videos; $68.97 \%$ of students prefer to record related variety Programs to increase interest in traditional culture; some students (37.59\%) want to receive information by clearly advertising.

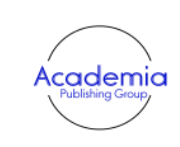

International Journal of Educational Studies

Vol. 2, No.3, pp. 163-170

2019

DOI: $10.53935 / 2641-533 x . v 2 i 3.118$

* Corresponding Author: Li Fenghui

Funding: This study received no specific

financial support.

Article History:

Received: 5 August 2019

Revised: 9 September 2019

Accepted: 7 October 2019

Published: 12 November 2019

(C) 2019 by the authors; licensee Academic

Publishing Group
Table-5. How to increase your interest in Chinese traditional culture (\% more).

\begin{tabular}{llllll}
\hline $\begin{array}{l}\text { Record related } \\
\text { short videos }\end{array}$ & $\begin{array}{l}\text { Record related Star } \\
\text { variety shows }\end{array}$ & $\begin{array}{l}\text { shooting Publishing related books not } \\
\text { related }\end{array}$ & and magazines & interested \\
\hline 67.04 & 68.97 & 37.59 & 56.37 & 2.6 \\
\hline
\end{tabular}

In addition, when asked the question that "Which form do you want to learn about traditional Chinese culture? (multiple choices)", the survey showed that "happy self-learning (61.84\%); interactive social activities (68.29\%) Organize to watch relevant video materials (58.72\%); hold related events or competitions $(55.38 \%)$.

Table-6. In what form do you want to learn to learn Chinese traditional culture? (multiple choice \%).

\begin{tabular}{lcclc}
\hline $\begin{array}{l}\text { Easy classroom happy } \\
\text { instruction }\end{array}$ & $\begin{array}{c}\text { self- interactive } \\
\text { learning }\end{array}$ & $\begin{array}{l}\text { Organize } \\
\text { social } \\
\text { activities }\end{array}$ & $\begin{array}{l}\text { relevant } \\
\text { materials }\end{array}$ & $\begin{array}{l}\text { watch hold related events } \\
\text { video or competitions }\end{array}$ \\
\hline 76.1 & 61.84 & 68.29 & 58.72 & 55.38 \\
\hline
\end{tabular}

It can be seen from the data that for traditional culture, whether from interest or actual contact, contemporary college students are more loyal to learning and inheriting excellent traditional culture through film and television programs and entertainment activities. It is true that the use of modern technology to carry 
out the study and inheritance of excellent traditional culture is only its related ways and means, but it cannot ignore the tendency of being too entertaining in this process.

\section{The Multiple Factors Affecting College Students' Understanding of Excellent Traditional Culture}

Based on the situation of more than 20,000 participants, contemporary college students' effects on excellent traditional culture, whether from the cognitive level or the practice field, are not satisfactory and have certain universality. There are multiple factors influencing and restricting the study and inheritance of excellent traditional culture by college students, which concluding the cultural itself, students, family, school, social environment and other reasons.

\subsection{From the Perspective of Culture Itself}

The economic foundation determines the superstructure, and culture as an ideological superstructure necessarily reflects the economic form of the time. There is no doubt that the Chinese traditional culture is the "root" and "soul" of the Chinese nation. It is an important theoretical and ideological source for the 5,000-year civilization. However, it should also be acknowledged that China's excellent traditional culture is based on agricultural civilization. It occurs and develops is a self-sufficient small-scale peasant economy. There is a certain gap compared with today's socialist market economy. At the same time, Chinese traditional culture is the core value of feudal society. It maintains the class interests of feudal rule represented by the landlord class. It must have its limitations of the times and classes, and needs creative transformation and innovative development.

\subsection{From the Perspective of Student Itself}

Confucius said that:"People can make the spirit flourish, rather than the spirit make people to improved." colleges and universities inherit and promote excellent traditional culture, students are the main body, and students' enthusiasm and initiative need to be exerted. From the current point of view, contemporary college students have a shallow understanding of excellent traditional culture, it is inseparable from the students' own reasons.

Firstly, college students lack initiative in the perception of excellent traditional culture. According to the survey data, the main channel for students to contact traditional culture is school education, accounting for $72.62 \%$. For the reading of extracurricular ancient books, the number who read 10 books accounting for $74.65 \%$. For the reading frequency of Chinese classics, the proportion of people who read occasionally reached $67.54 \%$. It can be seen that college students' understanding and contact with traditional culture are mostly limited to the classroom, but lack of active learning after class. This is one of the important reasons for college students to have a shallow understanding of excellent traditional culture.

Secondly, the tendency of pan-entertainment is more obvious. Putting the teaching method into entertainment to learn, and other various forms of practical activities, they are a kind of means of cultural inheritance. The purpose is to enable people to participate more actively in order to achieve a better understanding of cultural connotations, but just not for entertainment. Otherwise it is the end of the cart. Above survey data shows that college students have shown strong interest in practical activities and variety shows. When asked, "If you have the opportunity to participate in the activities of inheriting and protecting traditional culture, would you participate?", $87.86 \%$ of the respondents gave a positive answer. In addition, when college students can do something for traditional festivals, $88.36 \%$ of people choose to "actively participate in activities related to traditional festivals." When asked how to increase their interest in traditional culture, the top two are: recording related variety shows (accounting for 68.97\%) and recording short videos $(67.04 \%)$. Obviously, college students' perception of excellent traditional culture, they prefer to entertainment than understanding.

\subsection{From the Situation of Family}

Parents are the children's first teacher, and the family environment plays an irreplaceable role in the formation of students' personality and cultural literacy. Students' understanding of traditional culture is inseparable from the parents' words and deeds. Many traditional Chinese virtues are learned in subtle ways. According to the survey data, for "the main source of contact with traditional culture", family education is 
second only to school education, accounting for $66.66 \%$. However, the problem is that among the more than 20,000 students, the education level of parents is generally low. The mother's education level is mainly primary school (34.99\%), junior high school (32.27\%), and the father's education level is junior high school (39.71\%), high school / vocational high school / secondary school (27.88\%).From the perspective of history,contemporary college students born at the turn of the century, their parents were officially born before and after the "Cultural Revolution", just reverted to a historical period shortly after the college entrance examination, the education popularization was relatively low.In addition, in the late 1990s, it was the peak period for farmers to work in cities. The children born during this period were mostly left-behind children. It can be seen that contemporary college students lack a good family education environment. At the level of family education, the acquisition of traditional culture lacks the words and deeds of parents and elders.

\subsection{From the Perspective of School}

The school is the main place for teaching and educating people, and the school also bears an important responsibility for inheriting excellent traditional culture. The survey shows that the main source of traditional Chinese culture in contact with college students is school education $(72.62 \%)$. However, the school still has certain defects in the education of excellent traditional culture. From the survey data, "Does your school focus on the cultivation and development of traditional culture?",the proportion of generally paying attention and holding regular lectures is $50.5 \%$ and the proportion of not attention is above $17.56 \%$.As for the current view of traditional culture- related activities held by the school, $68.29 \%$ of the students are difficult to participate because of poor understanding; $63.78 \%$ of the students believe that the interaction of the activities is too small and the infection is weak; and $56.83 \%$ of the students feel that the form of activity is single and attractive.It can be seen that the education of traditional culture in colleges and universities is lack of subjective attention and the curriculum is not perfect. Most colleges and universities do not have a systematic general education course to spread excellent traditional culture, which causes college students to lose the main channels of receiving information and receiving education. The sporadic and fragmented knowledge is obviously incomparable compared with systematic and comprehensive learning. Second, the education and teaching activities related to traditional culture are mostly in the form. The lack of content enrichment and formal innovation in classroom theory teaching and extracurricular practice teaching is the main reason for the low participation of students. How to play the role of the main channel of classroom teaching and create a good atmosphere for carrying forward the excellent traditional culture is the key to solving the problem.

\subsection{From the Perspective of Multicultural Shock}

"Social ideology is complex and diverse, and intertwined. China's economic and social profound changes and profound adjustment of interests have made the ideology field more diverse and changeable. People's thinking is more active, independent, selective, versatile, The difference is significantly enhanced, and various ideas are mixed and various forces are competing to become the norm" (The Propaganda Department of the Central Committee of the Communist Party of China, 2018). Because the current university campus and society are basically "homogeneous", the thoughts and cultures of college students are becoming more diverse. In addition, the factors of the curiosity, the driving of hunting, the hype of merchants and media make the traditional culture being squeezed out. The various ideological and cultural cultures are on the paper, causing the traditional culture to lose its main position.

Historically, in modern times, with the decline of the feudal dynasty, China has been bullied, and the traditional culture that has been adapted to it has been affected. From Western learning to the "falling down the Kongjiadian" and the "Cultural Revolution",all the event showed that there is a prejudice against traditional culture. According to the survey data, when asked "What problems are currently facing traditional festivals?", $59.81 \%$ believe that they are affected by the foreign festival. In the Internet age, multiculturalism is ubiquitous in both explicit and implicit forms. In particular, hostile forces use the guise of cultural exchanges to promote the so-called "freedom and equality" of neoliberal ideas, to infiltrate culture, to export values, and to attempt to evolve through peace. The way to carry out the "color revolution." This undoubtedly has a negative impact on the formation of the correct values of the college students. As a result, some college students have a vague understanding of the rich connotation of excellent traditional culture and the spirit of mainstream value, the degree of recognition is reduced, and the practice is weakened.In addition, the "selfinterest" and "individualism" advocated by multiculturalism and the "goodwill, righteousness, wisdom and

Studies

Vol. 2, No.3, pp. 163-170

2019

DOir $10.53935 / 2641-533 x . v 2 i 3.118$

Corresponding Author: Li Fenghui

Funding: This study received no specific

financial support.

Received: 5 August 2019

Revised: 9 September 2019

Published: 12 November 2019

() 2019 by the authors; licensee Academic

Publishing Group 
trustworthiness" and "gentle,modest and courteous" in the excellent traditional Chinese culture are in conflict with each other, which is likely to cause college students to fall into moral predicament. How do colleges and universities cope with the impact of Western values? How to deal with the challenge of multiculturalism to reality? How to make college students recognize the true colors of Western culture? How to improve the vigilance of college students on cultural invasion and value output? How to promote excellent traditional culture and enhance cultural awareness and self-confidence? These have become important issues to continue to solve.

\section{The Strategies for Promoting Excellent Traditional Culture in Colleges and Universities}

"University is a place where people are talented and cultivate talents. It is a place where young people learn knowledge, grow their talents, and let their dreams fly" (Jinping's, 2018). Colleges and universities shoulder the important mission of cultivating talents, and they are also important places for moral education. How to better promote excellent traditional culture, constantly enriching the value of college students? What kind of strategy is adopted to guide traditional culture to achieve creative transformation and innovative development? This is a real problem currently facing.

\subsection{Grasping the Principle of Socialism}

The education of excellent traditional culture must be based on the basic principle of socialism and clarify that China is the nature of a socialist country. This is the basic premise and primary direction. The propaganda and education of excellent traditional culture in colleges and universities must always grasp the direction of the advanced socialist culture, adhere to the development path of socialist culture with Chinese characteristics, and strengthen the guiding position of Marxism in all aspects, always bearing the fundamental question in mind: "What kind of person to train, for whom to cultivate people."

First of all, the promotion of excellent traditional culture should be combined with the promotion of socialist core values, and we should combine the integration of excellent traditional cultural ideas with the education of socialist core values. Secondly, we will build a communication front of excellent traditional culture, and carry forward the combination of national spirit and the spirit of the times. Finally, we should persist the principle that "adhere to the socialist core values as the guide, adhere to creative transformation, innovative development, adhere to the Chinese cultural standpoint, inherit the Chinese cultural genes, not forget the original traditional culture and absorb the foreign culture,so that to continuously enhance the vitality and influence of China's excellent traditional culture, and create new glory of Chinese culture" (Opinions on implementing the inheritance and development project of Chinese excellent traditional culture, 2017).

\subsection{Strengthening the Construction of the Teaching Staff}

Promoting excellent traditional culture, the faculty team is essential. First of all, it is necessary to improve the humanistic quality of the overall teachers in colleges and universities, and to adhere to the combination of cultural education and self-cultivation. College teachers must not only be the "teachers" who preach the profession, but also cultivate the excellent traditional culture and become a "personal teacher" who is just as a norm. Secondly, it is necessary to equip a professional talent team to provide systematic and professional lectures on relevant courses, and provide effective protection for interested students to learn the traditional culture. Finally, college counselors play a very important role in the students work. College counselors work in conjunction with schools and colleges, and communicate with students in and out of class are the forefront of understanding student dynamics. They should give full play to the role of counselors in organizing and coordinating. It is necessary to use the spare time to carry out various forms of practical activities to stimulate students' understanding of traditional culture,such as regularly organize reading classics, theme classes, etc., so that to enrich the form of communication of excellent traditional culture.

\subsection{Improving the Supervision and Evaluation Mechanism}

《Opinions》 pointed out: "Party committees and governments at all levels must put the important work of the inheritance and development of Chinese outstanding traditional culture on the important agenda from the height of cultural self-confidence, persistence and development of socialism with Chinese characteristics, and the great rejuvenation of the Chinese nation. The evaluation system is included in the important content 
of teaching at party schools and administrative colleges at all levels" (Opinions on implementing the inheritance and development project of Chinese excellent traditional culture, 2017).

Policy guidance and sound mechanism are important guarantees for colleges and universities to promote excellent traditional culture. First of all, the teaching effect of excellent traditional culture is incorporated into the teacher assessment system. Taking students' thoughts, culture and morality as important evaluation indicators, constructing a scientific work evaluation mechanism, and setting up a good supervision and evaluation system and framework for all aspects and teachings of excellent traditional culture teaching. Second, improve the teacher evaluation system. In order to prevent the related supporting courses from flowing in form, colleges and universities can set up a curriculum supervision group to conduct comprehensive evaluation of related courses, select high- quality courses, quality courses and rewards with the combination of expert sampling and student evaluation feedback so that to make virtuous circle of excellent traditional culture teaching.

\subsection{Optimizing the School Curriculum Design}

On January 25, 2017, the Opinions on the Implementation of the Excellent Traditional Culture Heritage Development Project issued and implemented by the General Office of the CPC Central Committee and the General Office of the State Council mentioned: "Promoting the establishment of Chinese outstanding traditional culture compulsory courses in the philosophy and social sciences And the content of Chinese outstanding traditional culture is added to related disciplines and courses. Strengthen the construction of relevant disciplines of Chinese excellent traditional culture, and attach importance to the protection and development of "out of school" and unpopular subjects with important cultural values and inheritance significance." This requires universities to pay attention to the promotion and education of excellent traditional culture from the curriculum. According to the survey, $35.36 \%$ of the respondents indicated that their school did not have a school-based curriculum on traditional culture. It can be seen that there is still a large room for improvement in the curriculum. Carrying forward the excellent traditional culture has a long way to go.

First, build a "stereo" teaching model. Colleges and universities can carry out the education of excellent traditional culture from the beginning of school to the graduation, promote the effective integration of the first classroom, the second classroom and the third classroom, deeply explore the traditional cultural elements in teaching activities, construct theoretical teaching, practice teaching,special research, and multi-platform support of the three- dimensional teaching mode. Second, improve the curriculum. According to the actual situation, colleges and universities can set up the basic course of Chinese studies as a general compulsory course to enhance the general cognition of college students on excellent traditional culture. At the same time, supplemented by professional elective courses, students can selectively study in depth according to their own interests. Compulsory, elective, basic and professional courses are coordinated to create a good cultural atmosphere and a reasonable training mechanism. Finally, innovative classroom teaching mode. It is the key to give a good understanding of the Chinese traditional culture, to thoroughly understand the main channels of classroom education, and to give full play to the role of the first classroom. According to the survey data, $76.1 \%$ of the people are more inclined to contact with the traditional culture of the school with easy classroom teaching.It can be seen that the choice of teaching mode is especially important for the promotion of excellent traditional culture. Today, with advanced technology, colleges and universities should make full use of network technology and network resources to teach traditional culture to create a relaxed and pleasant classroom environment. It is necessary to explain the teacher, interspersed with the film and television materials, and combine the students' discussion; it is necessary to promote the excellent traditional culture in the overall cognition of the college students with the teaching mode supplemented by the curriculum and supplemented by practical teaching. In addition, we actively promote the combination of Chinese learning knowledge with other courses. Chinese culture is profound and profound, and on the basis of adhering to Marxist standpoints, viewpoints and methods, under the premise of not changing the completeness of other courses' theoretical systems, actively integrate Chinese excellent traditional culture into other courses, and combine the characteristics of each course to guide Students' theoretical cognition of excellent traditional culture, emotional identity and behavioral externalization.

International Journal of Educational
Studies
Vol. 2 , No.3, pp. $163-170$
2019
DOI: $10.53935 / 2641-533 x . v 2 i 3.118$
Eorresponding Author: Li Fenghui
Funding: This study received no specific
financial support.
Article History:
Received: 5 August 2019
Revised: 9 September 2019
Accepted: 7 October 2019
Published: 12 November 2019
() 2019 by the authors; licensee Academic
Publishing Group

| 169 


\subsection{Innovating the Transmission Media on Society}

Integrating excellent traditional culture into the campus, entering the dormitory, and playing the role of environmental education, requires innovative media. According to survey data, college students are more willing to accept excellent activities in community activities, practical activities, and variety shows to learn excellent traditional culture. Therefore, in the educational mediation of colleges and universities, one must adhere to the position of traditional culture. Such as the opening of national studies lectures, forums, cultural salons, founding associations; teaching buildings, dormitory posting slogans, famous sayings, etc., so that traditional culture is integrated into the campus culture, Chinese knowledge into the brain, into the heart, into the line. The second is to make full use of the new media platform. Filming micro-movies related to traditional culture, short videos and other film and television materials that students like to see, expand the influence of excellent traditional culture, and guide students to participate. The third is to actively play the role of network education.According to the "Statistical Report on Internet Development in China", "In 2018, the average online time of Internet users in China was 27.6 hours, which was 0.6 hours higher than that at the end of 2017. Among the netizens in China, the largest group of students, accounting for 25.4\%" (Anonymous, 2021). Where are people, where is the education work, colleges and universities should make full use of Weibo, WeChat, mobile phone client to spread excellent traditional culture, actively create educational theme websites based on excellent traditional culture, spread well to college students, and promote excellent traditional culture. At the same time, the flag of critique is a pseudo-nationalistic thought in the name of inheritance. In addition, we will actively develop educational channels such as Guoxue APP and the public number, provide high-quality "excellent traditional cultural resource packages", enrich the emotional experience of college students, unite the synergy of online and offline education, and enhance students' awareness of excellent traditional culture.

\section{References}

Anonymous. (2021). Anonymous The 43rd statistical report on internet development in China. Retrieved from: http://www.cac.gov.cn/wxb_pdf/0228043.

Jinping's, X. (2014). Speech at the opening ceremony of the 5th anniversary of confucius' birthday and the opening ceremony of the Paper presented at the 5th General Assembly of the International Confucian Association, People's Daily.

Jinping's, X. (2018). Speech at the peking university teacher-student symposium. People's Daily.

Neil. (2004). Postman Amusing ourselves to death. Guilin: Guangxi Normal University Press.

The Propaganda Department of the Central Committee of the Communist Party of China. (2018). Xi jinping's 30th new era of socialism with Chinese characteristics (pp. 215). Beijing: Learning Press.

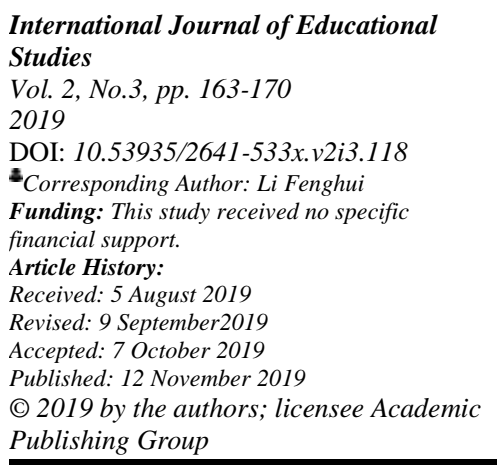

$\mid 170$ 